\title{
New Approach to Achieve High Strength Powder Metallurgy Ti-6Al-4V Alloy through Accelerated Sintering at $\beta$-Transus Temperature and Hydrogenation-dehydrogenation Treatment
}

\author{
Fei Cao, K.S. Ravi Chandran*, Pankaj Kumar \\ Metallurgical Engineering, the University of Utah, Salt Lake City, Utah 84112, USA \\ *Corresponding author E-mail: ravi.chandran@utah.edu
}

It is demonstrated that high density powder metallurgy (PM) Ti-6Al-4V alloy, with a finer prior- $\beta$ grain size, can be achieved by vacuum sintering of $\mathrm{TiH}_{2}$ compacts at the $\beta$-transus $\left(1010{ }^{\circ} \mathrm{C}\right)$ temperature, taking advantage of the accelerated self-diffusion. The subsequent refinement of the coarse lamellar microstructure by hydrogenation-dehydrogenation treatment produces a high tensile strength ( $1130 \mathrm{MPa})$ and ductile $(\sim 10 \%)$ alloy. The superior tensile strength and ductility result from the nanoscale Widmanstatten structure and the finer prior- $\beta$ grain size, respectively, created by the two treatments. The results show a promising pathway to make high strength and ductile PM titanium alloys.

Keywords: Titanium, Powder metallurgy, Tensile strength, Ductility, Grain size

There is a large volume of work on PM titanium alloys, since the 1970s, aimed at near-net shape manufacturing of components. However, wide spread application has not been successful due to subpar densities, low mechanical properties, and high cost of manufacturing [1,2]. Previous works [3,4,5] on PM titanium focused on vacuum sintering of blended elemental (BE) powders in the $\beta$-phase field, typically $>1200{ }^{\circ} \mathrm{C}$. The major problem in this approach is that large prior- $\beta$ grains and coarse lamellar colony structures are created, leading to a relatively low tensile and fatigue strength $[2,3]$. Therefore, approaches to accelerate densification, refine $\alpha+\beta$ microstructure, and improve mechanical properties without mechanical working, are critically needed to create competitive PM titanium alloys.

Recently, work from our group [6] showed that a very fine $\alpha+\beta$ microstructure in Ti-6Al-4V alloy can be produced by hydrogen-sintering-and-phase-transformation (HSPT) process. The alloy composition meets the ASTM-B348 composition specification for wrought Ti-6Al-4V, especially the 
oxygen content ( $\sim 0.2$ wt.\%). This alloy had a tensile strength of $1033 \mathrm{MPa}$ and an elongation of $13.7 \%$ [7]. After the heat treatment to produce a bimodal microstructure, the tensile strength and ductility levels were $1076 \mathrm{MPa}$ and $11.9 \%$, respectively [8]. These strength and ductility levels are higher than that required to meet the ASTM alloy specification. Jia et al. [9] claim that a tensile strength of $1422 \mathrm{MPa}$ and a ductility of $7.2 \%$ elongation was achieved in Ti-6Al-4V alloy with a very high oxygen level $(\sim 0.52$ wt.\%) made by forging and heat treatment. This material cannot be classified as ASTM Ti-6Al-4V alloy for several reasons. Not only the oxygen content in this material had highly deviated from the ASTM standard, the ductility level claimed seems to be questionable. This is because extensive studies $[10,11]$ on PM Ti-6Al-4V alloys, have shown, consistently, that ductility decreases to about $2 \%$ with O levels > $\sim 0.4$ wt.\%. Regardless, for meaningful gains in strength and ductility relative to the ASTM standard levels, they must be achieved without any deviation from ASTM specification and without the use of additional mechanical working or heat treatment steps after PM consolidation of Ti-6Al-4V.

The objective of this work is to demonstrate a new, easily implementable, PM processing approach that can lead to high density PM titanium alloys with higher strength and ductility levels. It is shown that this can be achieved while still conforming to ASTM specification for oxygen level, and, without using any additional mechanical working or heat treatment. The technique uses, first, vacuum sintering of $\mathrm{BE}$ compacts at the $\beta$-transus temperature $\left(1010{ }^{\circ} \mathrm{C}\right)$, followed by a hydrogenationdehydrogenation $(\mathrm{HDH})$ at a lower temperature, with the intent to keep the processing costs as low as possible. There are two hypotheses to be tested in this context: (i) the anomalously high self-diffusion in Ti should lead to accelerated sintering at the $\beta$-transus temperature and should result in finer prior- $\beta$ grains, and, (ii) the subsequent refinement of microstructure in the HDH step should lead to a large increase in strength without sacrificing ductility too much.

In this study, the PM Ti-6Al-4V alloy samples were sintered starting from cold-isostatic-pressed (350 MPa) cylindrical bars made from the blended mixture of $\mathrm{TiH}_{2}$ powder (-325 mesh, Reading Alloys, Inc., PA) and 60Al-40V (wt.\%) master alloy powder (-400 mesh, Reading alloys Inc., PA). The compacts 
were vacuum sintered (VS) either at the $\beta$-transus temperature of $1010{ }^{\circ} \mathrm{C}$ (named $1010 \mathrm{VS}$ ) or at $1200{ }^{\circ} \mathrm{C}$ (named 1200VS) for 8 hours under vacuum $(<0.001 \mathrm{~Pa})$. Some of the VS samples were given hydrogenation-dehydrogenation treatment $(\mathrm{HDH})$ to refine the microstructure. In this process, the samples, after vacuum sintering, were cooled at a rate of $10{ }^{\circ} \mathrm{C} / \mathrm{min}$ to the hydrogenation temperature (Fig 1(a)). Then the hydrogenation was done ( 1 atm. pressure of $\mathrm{H})$ at $850{ }^{\circ} \mathrm{C}$ for 2 hours, followed by dehydrogenation at $650{ }^{\circ} \mathrm{C}$ in vacuum for 15 hours. It is to be noted that these temperatures are near the lowest possible hydrogenation and dehydrogenation temperatures and were selected on the basis of Ti-H phase diagram by Kerr et al.[12,13]. The hydrogenation at $850{ }^{\circ} \mathrm{C}$ for 2 hours was found to lead to about 0.7 wt.\% $\mathrm{H}$ in solution in $\beta$ titanium, which is slightly larger than the minimum $(\sim 0.6 \mathrm{wt} . \%)$ required for eutectoid transformation [13].

The 1010VS and 1200VS samples that received $\mathrm{HDH}$ treatment are hereafter referred to as 1010VSHDH and 1200VSHDH, respectively. Microstructures and elemental distributions were imaged using optical, scanning electron (Quanta 600F) and transmission electron microscopes (JEM-2800). ASTM E-8 standard tensile bars (6.35 mm diameter, $38.1 \mathrm{~mm}$ gage length) were machined from the sintered bars. The tensile tests were performed at room temperature with a strain rate of $10^{-3} \mathrm{~S}^{-1}$ and strains were measured using extensometer. At least three tests were performed for each treatment condition and the stress-strain curves were highly reproducible.

Spectroscopic analysis indicated that samples met the ASTM B-348 specification for the PM Ti6Al-4V alloy. The levels of $\mathrm{O}, \mathrm{H}$ and $\mathrm{N}$ (analyzed by LECO TCH600) in the sintered samples were determined to be (in wt.\%) $0.221,0.00073$ and 0.0193 , respectively. Table I reports the average densities and tensile properties. All the samples achieved densities $\geq 99 \%$. First, it is interesting to see that the 1010VS sample, sintered at the $\beta$-transition temperature, achieved a density of $\sim 99 \%$. This is relatively high, compared to the densities [3] obtained in vacuum sintering of BE compacts at $1260{ }^{\circ} \mathrm{C}$, which are in the range of 95-99\%. This high degree of densification, at the lowest possible temperature in $\beta$-phase field, is due to the enhanced self-diffusivity in Ti near the phase transition temperature, as illustrated in Fig. 
1(b). Titanium exhibits anomalous, elevated self-diffusion behavior $[14,15]$ near the $\beta$-transus and on the side of the $\beta$-phase. The self-diffusion co-efficient of pure titanium is $6.5 \times 10^{-10} \mathrm{~cm}^{2} / \mathrm{s}$ at the $\beta$-transus, which is quite close to that $\left(9.6 \times 10^{-9} \mathrm{~cm}^{2} / \mathrm{s}\right)$ at $1200{ }^{\circ} \mathrm{C}[15]$. The diffusivity at the $\beta$-transus temperature is also significantly higher than that extrapolated from the data of diffusion in $\alpha$-phase $\left(1.3 \times 10^{-12} \mathrm{~cm}^{2} / \mathrm{s}\right.$ at $880{ }^{\circ} \mathrm{C}$ ) [15]. Sanchez and De Fontaine [16] explained the diffusion enhancement as due to phase fluctuations at the crystallographic level associated with the formation of omega $(\omega)$ precursor phases. In addition, Bokshteyn et al. [14], argue that the local diffusion along $\beta-\omega$ interphase boundaries is 3-4 orders of magnitude higher than the diffusion in the $\beta$-phase. Thus, the high density achieved at by $\beta$ transus sintering is attributed to the accelerated diffusion arising from both effects.

Microstructures of the VS and VSHDH samples are shown in Fig. 2. The X-ray diffraction data presented in the (supplementary section), indicates that the microstructures have fully transformed after the treatments. Figs. 2(a) and (b) are the optical micrographs of 1010VS and 1200VS samples, respectively, showing the coarse lamellar microstructures. A significant difference in the average size of prior- $\beta$ grain size is seen-about $67 \mu \mathrm{m}$ in 1010VS whereas it is $213 \mu \mathrm{m}$ in $1200 \mathrm{VS}$. The lower prior- $\beta$ grain size is clearly due to the lower sintering temperature of 1010VS. It is to be note that an average prior- $\beta$ grain size less than $100 \mu \mathrm{m}$, with $99 \%$ density, has not been achieved before by vacuum sintering. The prior- $\beta$ grain sizes obtained by VS of PM Ti-6Al-4V alloys are normally $>100 \mu \mathrm{m}$, at densities of $95-$ $99 \%[2,3]$.

The microstructures of HDH treated samples, 1010VSHDH and 1200VSHDH, are presented in Figs. 2(c) and (d), respectively. The average sizes of the prior- $\beta$ grains in 1010VSHDH and 1200VSHDH samples are $71 \mu \mathrm{m}$ and $221 \mu \mathrm{m}$, respectively. This indicates that the HDH treatment did not alter the prior- $\beta$ grain size much. The SEM imaging of both samples showed the presence of very fine Widmanstatten microstructure (shown in Fig. 2(e) for 1010VSHDH as example), as a result of the eutectoid transformation $[12,13]\left(\beta_{\mathrm{H}} \rightarrow \alpha+\right.$ hydride). The TEM image (Fig. 2(f)) indicates that the widths of $\alpha$ grains are in hundreds of nanometers. The microscale distribution $\mathrm{Al}$ and $\mathrm{V}$ corresponding to Fig. 2(f) 
are shown in Figs. 2(g) and 2(h), respectively. The elemental map indicates that $\mathrm{Al}$ and $\mathrm{V}$ is largely segregated in $\alpha$ and $\beta$ phases, suggesting the formation of a fully equilibrated $\alpha+\beta$ microstructure after the HDH treatment.

Table I shows the tensile properties of the present PM Ti-6Al-4V alloys. Fig. 3 shows the representative stress-strain curves. The tensile stress-strain curve of mill-annealed wrought Ti-6Al-4V alloy, having a fine equiaxed microstructure $(5.6 \mu \mathrm{m}$ grain size $)$ is also included as reference. Both the VS samples have ductility levels comparable to that of the mill-annealed alloy. However, the tensile strengths are about $10 \%$ lower than that of the mill-annealed alloy, which is due to the coarse lamellar microstructure. Strength of the lamellar microstructure in titanium is weakly affected by its colony size [17]. The larger prior- $\beta$ grain size and the slip continuity across $\alpha / \beta$ interfaces, increases the mean-freeslip-distance during plastic deformation. Hence the larger prior- $\beta$ grain size of the lamellar microstructure $(221 \mu \mathrm{m})$ compared to the reference fine equiaxed $\alpha$ microstructure is expected to produce a relatively low strength.

The refined microstructure after the $\mathrm{HDH}$ treatment has the largest impact on strength- the tensile strength levels of both 1010VSHDH and 1200VSHDH samples increased by more than $200 \mathrm{MPa}$, relative to the VS counterparts. The yield and tensile strengths are comparable between 1010VSHDH and 1200VSHDH, indicating that it is the nanoscale Widmanstatten microstructure that controls the strength. More importantly, the tensile strength levels of HDH samples are about $200 \mathrm{MPa}$ higher than that of wrought Ti-6Al-4V,[8] and 60-100 MPa higher than that of HSPT-processed alloys [7]. The strength and ductility are comparable to that achieved by Kerr [13] using HDH treatment in wrought alloy. The slightly higher oxygen content $(0.22 \mathrm{wt} \%)$ in the present alloy would cause a small increase in strengtha 0.02 wt.\% increase in $\mathrm{O}$ increases strength by about $20 \mathrm{MPa}$ [11]. Thus, the increase in tensile strength in HDH samples can be largely attributed to the nanoscale Widmanstatten microstructure.

An interesting aspect is that the ductility of HDH samples showed a much higher sensitivity to the microstructure, than to the porosity or density. Although the ductility levels have decreased after the HDH 
treatment, the surprising finding is that the ductility of 1010VSHDH specimens is about $3 \%$ higher than that of the 1200VSHDH sample, even though the former samples have $0.8 \%$ lower density. Fractography was performed to explain the tensile ductility trends on the basis of fracture mechanisms. Figs. 4(a) and 4(b) show the transgranular ductile fracture of 1010VS and 1200VS samples, respectively. Figs. 4(c) and 4(d) show the ductile fracture in 1010VSHDH and 1200VSHDH samples, respectively. The ductile voids here are much smaller than that in VS samples, and this is due to the fine scale microstructure of HDH treated samples. The fracture surface of $1200 \mathrm{VSHDH}$ sample contained a higher proportion of ductile intergranular fracture (DIF). In contrast, the 1010VSHDH sample did not show any intergranular mode, and the entire fracture was completely transgranular and ductile. Fig. 4(e) shows the enlarged transgranular ductile fracture region in 1010VSHDH sample. Fig. 4(f) shows the enlarged intergranular ductile fracture region in Fig. 4(d), revealing the fact that the ductile fracture is actually localized in the GB- $\alpha$ along the prior $\beta$ grain boundaries. However, the average sizes of voids in VSHDH specimens are much smaller than that in VS specimens due to much finer $\alpha$ grain size. The relatively lower ductility of HDH samples is probably due to the reduced extent of void growth before failure.

The DIF is a unique characteristic of tensile fracture of titanium alloys having a GB- $\alpha$ phase, as shown by Greenfield and Margolin [ 18,19]. They showed that, in Widmanstatten microstructures, ductile fracture initiated by void formation occurring along the interfaces of GB- $\alpha$. This explains the observation of a higher proportion of intergranular fracture in 1200VSHDH specimens with relatively coarse prior- $\beta$ grains. However, this intergranular fracture mode is completely absent in 1010VSHDH samples, even though some GB- $\alpha$ is present at prior- $\beta$ grain boundaries in this microstructure. This suggests that the larger prior- $\beta$ grain size is the principal cause of low ductility, although the fracture mechanism itself shows up as GB- $\alpha$ ductile fracture. Thus, the relatively higher ductility in 1010VSHDH sample, relative to $1200 \mathrm{VSHDH}$, can be explained on the basis of its finer prior- $\beta$ grain size, avoiding intergranular fracture along the $\beta$ grain boundaries. The benefit of fine prior- $\beta$ grain size created by the $\beta$-transus 
sintering thus outweighs any degradation in ductility due relatively less density (99\%) obtained at this sintering temperature.

In summary, the major contribution of this work is the demonstration that a high strength and ductility combination can be achieved by controlling $\alpha$ grain size to increase strength and by controlling prior- $\beta$ grain size to increase ductility. Vacuum sintering just at the $\beta$-transus is sufficient to achieve a high density (>99\%) and homogenize all solution elements, a benefit of accelerated self-diffusion near the phase transition temperature. The resulting microstructure has nearly the same tensile ductility and a tensile strength about $10 \%$ lower than that of the reference mill-annealed Ti-6Al-4V microstructure. Further, it is demonstrated that hydrogenation-dehydrogenation treatment after vacuum sintering at $\beta$ transus produces a PM Ti-6Al-4V alloy with a nanoscale Widmanstatten microstructure that can attain a very high strength level while retaining good ductility. It should be mentioned, however, that the hydrogenation-dehydrogenation treatment, without the $\beta$-transus sintering step, is not capable of producing the desired combination of strength and high ductility, due to the failure localization along the boundaries of large prior- $\beta$ grains. The two stage treatment approach, in combination, has been shown be essential to produce a high strength microstructure with a good ductility. This approach should be helpful to design high strength PM titanium alloys in future.

\section{Acknowledgements}

The authors gratefully acknowledge funding support from the US Department of Energy, Innovative Manufacturing Initiative (DEEE0005761), through the Advanced Manufacturing Office and the Office of Energy Efficiency and Renewable Energy.

\section{References}

[1] A.K. Sachdev, K. Kulkarani, Z.Z. Fang, R. Yang, V. Girshov, JOM 64(5) (2012) 553-565.

[2] F.H. Froes, D. Eylon, Int. Mater. Rev. 35(3) (1990) 162-182.

[3] P.J. Anderson, V.M. Svoyatytsky, F.H. Froes, Y. Mahajan, D. Eylon, Modern Develop. Powder Metall. 13 (1981) 537-549. 
[4] F.H. Froes, S.J. Mashl, V.S. Moxson, J.C. Hebeisen, V.A. Duz, JOM November (2004) 46-48.

[5] V.S. Moxson, P. Sjoblom, M.J. Trzcinski, Adv. Powder Metall. 6 (1992) 125-140.

[6] P. Sun, Z.Z. Fang, M. Koopman, Y. Xia, J. Paramore, K.S. Ravi Chandran, Y. Ren, J. Lu, Metall. Mater. Trans. A 16 (2015) 1-15.

[7] F. Cao, K.S. Ravi Chandran, P. Kumar, P. Sun, Z.Z. Fang, M. Koopman, Metall. Mater. Trans. A 47(5) (2016) 2335-2345.

[8] J.D. Paramore, Z.Z. Fang, P. Sun, M. Koopman, K.S. Ravi Chandran, M. Dunstan, Scripta Mater. 107 (2015) 103-106.

[9] M.T. Jia, D.L. Zhang, B. Gabbitas, J.M. Liang, C. Kong, Scripta Mater. 107 (2015) 10-13.

[10] Y. Itoh, T. Uematsu, K. Sato, H. Miura, J. Jan. Soc. Powder Powder Metall. 56(5) (2009) 259-263.

[11] M. Yan, W. Xu, M.S. Dargusch, H.P. Tang, M. Brandt, M. Qian, Powder Metall. 57(4) (2014) 251257.

[12] W.R. Kerr, P.R. Smith, M.E. Rosenblum, F.J. Gurney, Y.R. Mahajan, and L.R. Bidwell: Titanium '80, Science and Technology, Proceedings of the 4th International Conference on Titanium., Metall. Soc. of AIME, Kyoto, Japan, 1980, pp. 2477-2486.

[13] W.R. Kerr, Metall. Mater. Trans. A 16 (1985) 1077-1087.

[14] S.Z. Bokshteyn, N.P. Zyulina, O.V. Markovich, Phys. Met. Metall. 68(1) (1989) 103-108.

[15] B. Sarma, K.S. Ravi Chandran, Acta Mater. 59 (2011) 4216-4228.

[16] J.M. Sanchez, D. de Fontaine, Acta Metall. 26 (1978) 1083-1095.

[17] D. Banerjee, J.C. Williams, Acta Mater. 61 (2013) 844-879.

[18] H. Margolin, Y. Mahajan, Metall. Trans. A 9 (1978) 781-791.

[19] M.A. Greenfield, H. Margolin, Metall. Trans. 3 (1972) 2649-2659. 


\section{List of Tables:}

Table I Tensile properties of Ti-6Al-4V alloy on the basis of average values from 3-6 samples for each treatment. Standard deviations are given in parentheses.

\section{Figure Captions:}

Fig. 1 (a) Temperature-time profile for vacuum sintering and hydrogenation-dehydrogenation treatments in PM Ti-6Al-4V alloy processing, and (b) schematic of the enhancement of self-diffusion and the anomalous diffusion region in titanium near $\alpha / \beta$ phase transition temperature $[14,15]$.

Fig. 2 Optical micrographs of (a) 1010 VS, (b) 1200 VS, (c) 1010 VSHDH, (d) 1200 VSHDH Ti-6Al-4V samples, (e) back scattered electron image and (f) STEM image of 1010 VSHDH microstructure, and (g) vanadium distribution and (h) aluminum distribution in (f).

Fig. 3 Stress-strain curves of (a) $1010^{\circ} \mathrm{C}$ sintered samples, and (b) $1200^{\circ} \mathrm{C}$ sintered samples.

Fig. 4 Fractographs of tensile fracture in PM Ti-6Al-4V samples, (a) 1010VS, (b) 1200VS, (c) 1010VSHDH, and (d) 1200VSHDH, (e) magnified view of (c), (f) magnified view of intergranular fractured region in (d). 
Table I Tensile properties of Ti-6Al-4V alloy on the basis of average values from 3-6 samples for each treatment. Standard deviations are given in parentheses.

\begin{tabular}{ccccccc}
\hline $\begin{array}{c}\text { Treatment } \\
\text { ID }\end{array}$ & $\begin{array}{c}\text { Density } \\
(\%)\end{array}$ & $\begin{array}{c}\text { Prior } \beta \\
\text { grain size }(\mu \mathrm{m})\end{array}$ & $\begin{array}{c}\text { Yield Strength } \\
(\mathrm{MPa})\end{array}$ & $\begin{array}{c}\text { Ultimate Tensile } \\
\text { Strength }(\mathrm{MPa})\end{array}$ & $\begin{array}{c}\text { Elongation } \\
(\%)\end{array}$ & $\begin{array}{c}\text { Reduction } \\
\text { Area }(\%)\end{array}$ \\
\hline $1010 \mathrm{VS}$ & 98.96 & 67 & $821( \pm 3)$ & $908( \pm 2)$ & $15.8( \pm 0.5)$ & $26.9( \pm 0.9)$ \\
$1010 \mathrm{VSHDH}$ & 99.02 & 71 & $1049( \pm 8)$ & $1128( \pm 5)$ & $10.5( \pm 0.3)$ & $21.8( \pm 1.2)$ \\
$1200 \mathrm{VS}$ & 99.80 & 213 & $841( \pm 2)$ & $935( \pm 1)$ & $16.6( \pm 1.0)$ & $30.6( \pm 0.3)$ \\
$1200 \mathrm{VSHDH}$ & 99.81 & 221 & $1053( \pm 3)$ & $1134( \pm 4)$ & $7.7( \pm 0.6)$ & $13.6( \pm 0.4)$ \\
Mill-annealed & 100 & $5.6^{*}$ & $912( \pm 2)$ & $1011( \pm 3)$ & $16.2( \pm 0.1)$ & $41.9( \pm 0.2)$ \\
\hline
\end{tabular}

* Average $\alpha$ grain size 


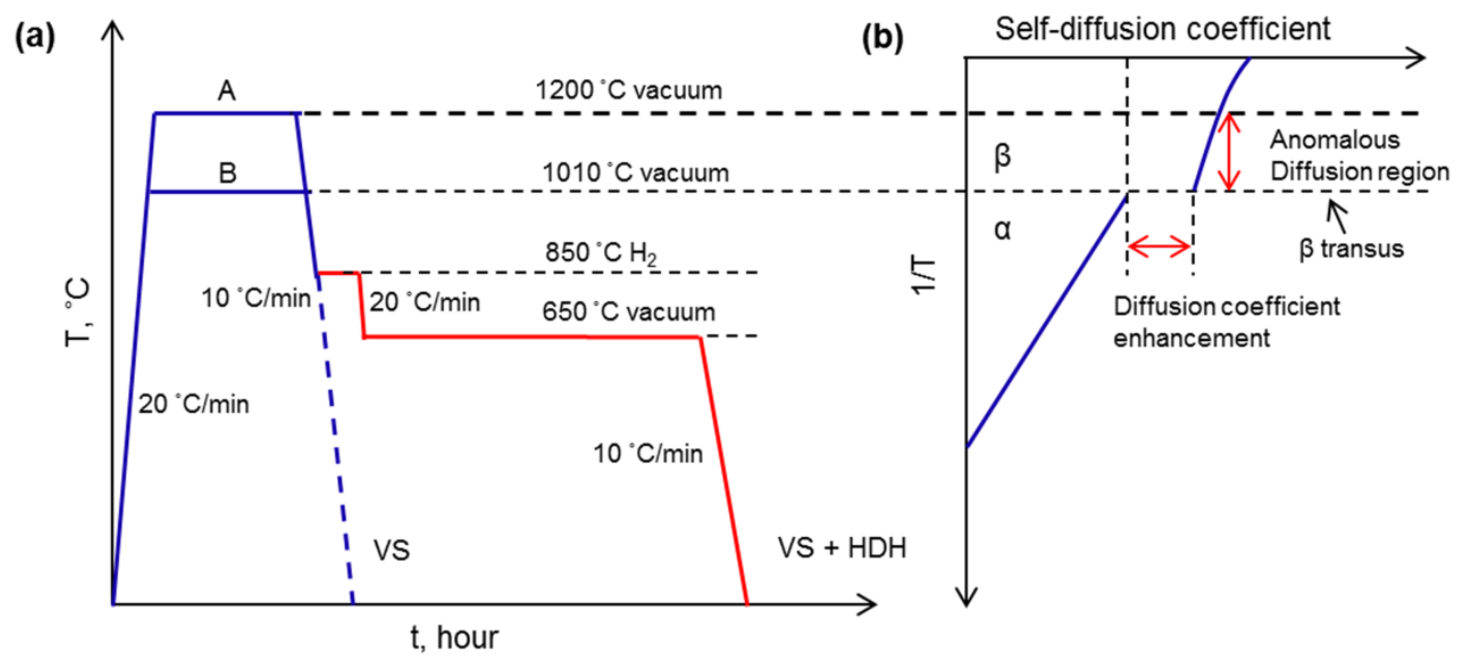

Fig. 1 (a) Temperature-time profile for vacuum sintering and hydrogenation-dehydrogenation treatments in PM Ti-6Al-4V alloy processing, and (b) schematic of the enhancement of self-diffusion and the anomalous diffusion region in titanium near $\alpha / \beta$ phase transition temperature $[14,15]$. 


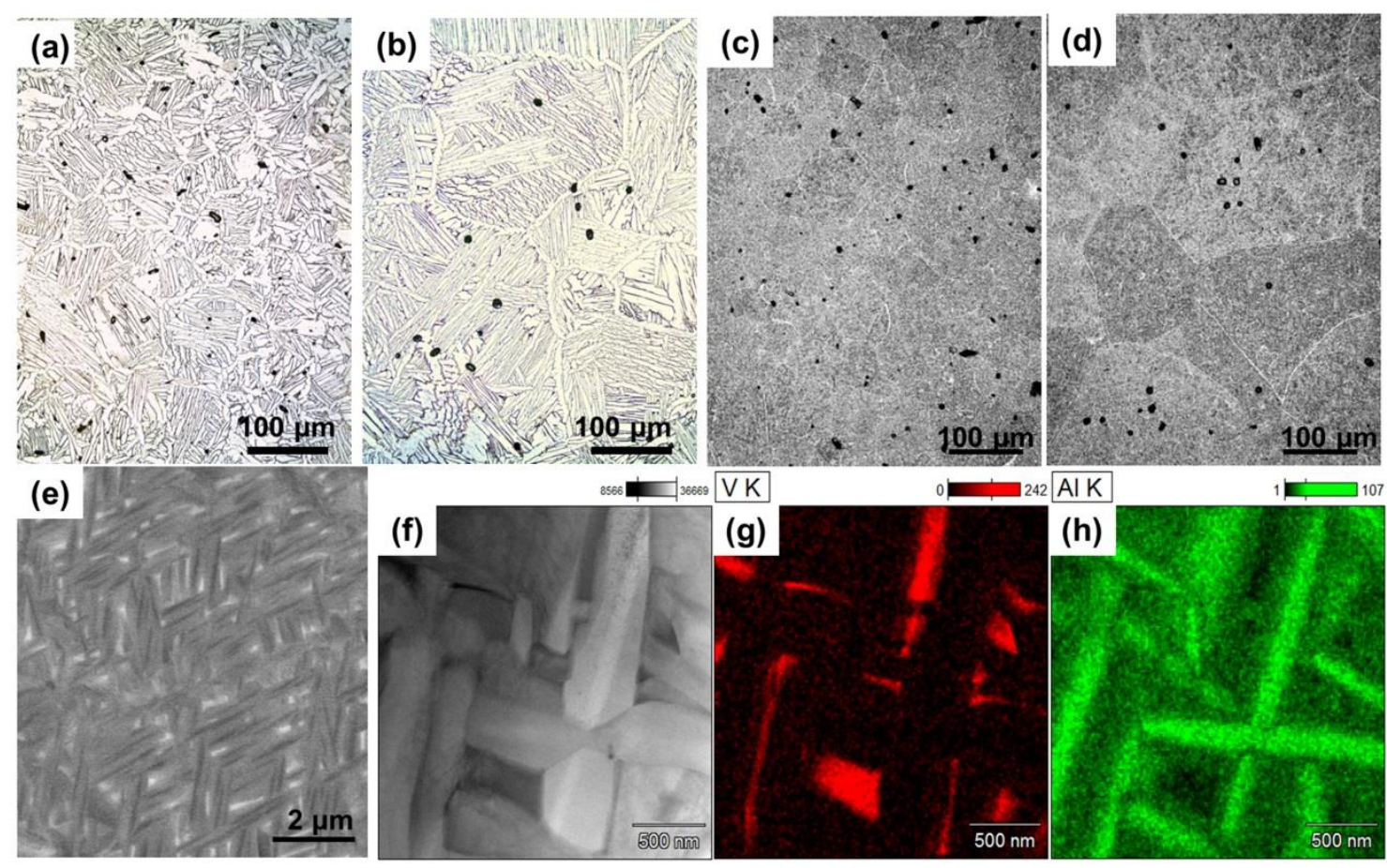

Fig. 2 Optical micrographs of (a) 1010 VS, (b) 1200 VS, (c) 1010 VSHDH, (d) 1200 VSHDH Ti-6Al-4V samples, (e) back scattered electron image and (f) STEM image of 1010 VSHDH microstructure, and (g) vanadium distribution and (h) aluminum distribution in (f). 

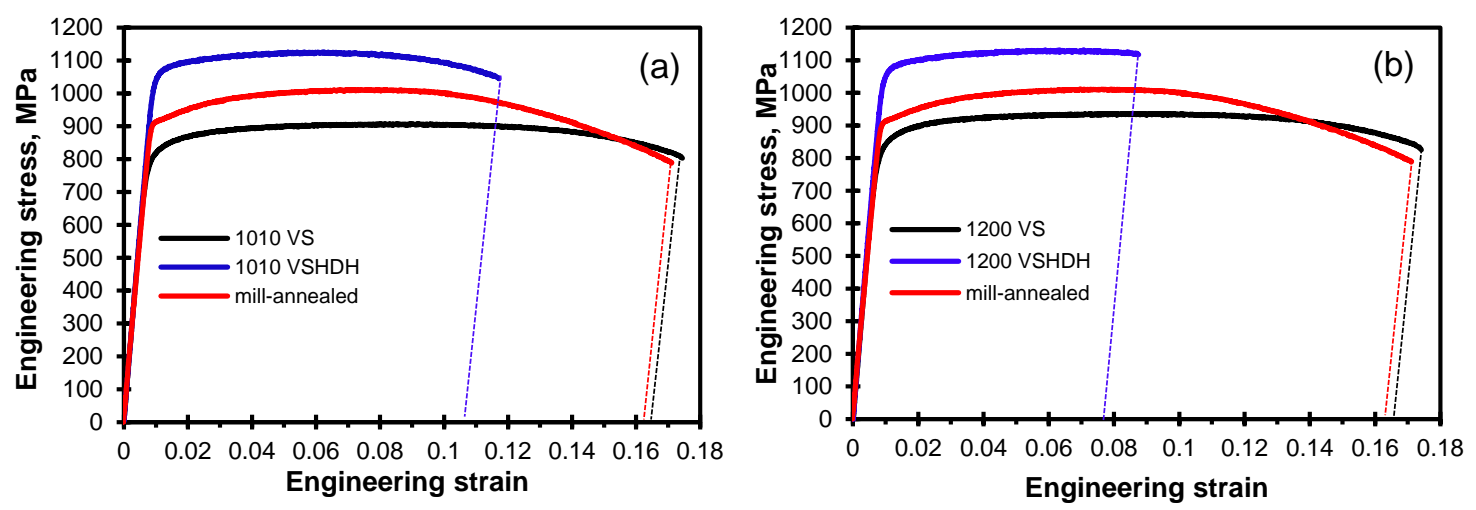

Fig. 3 Stress-strain curves of (a) $1010^{\circ} \mathrm{C}$ sintered samples, and (b) $1200^{\circ} \mathrm{C}$ sintered samples. 

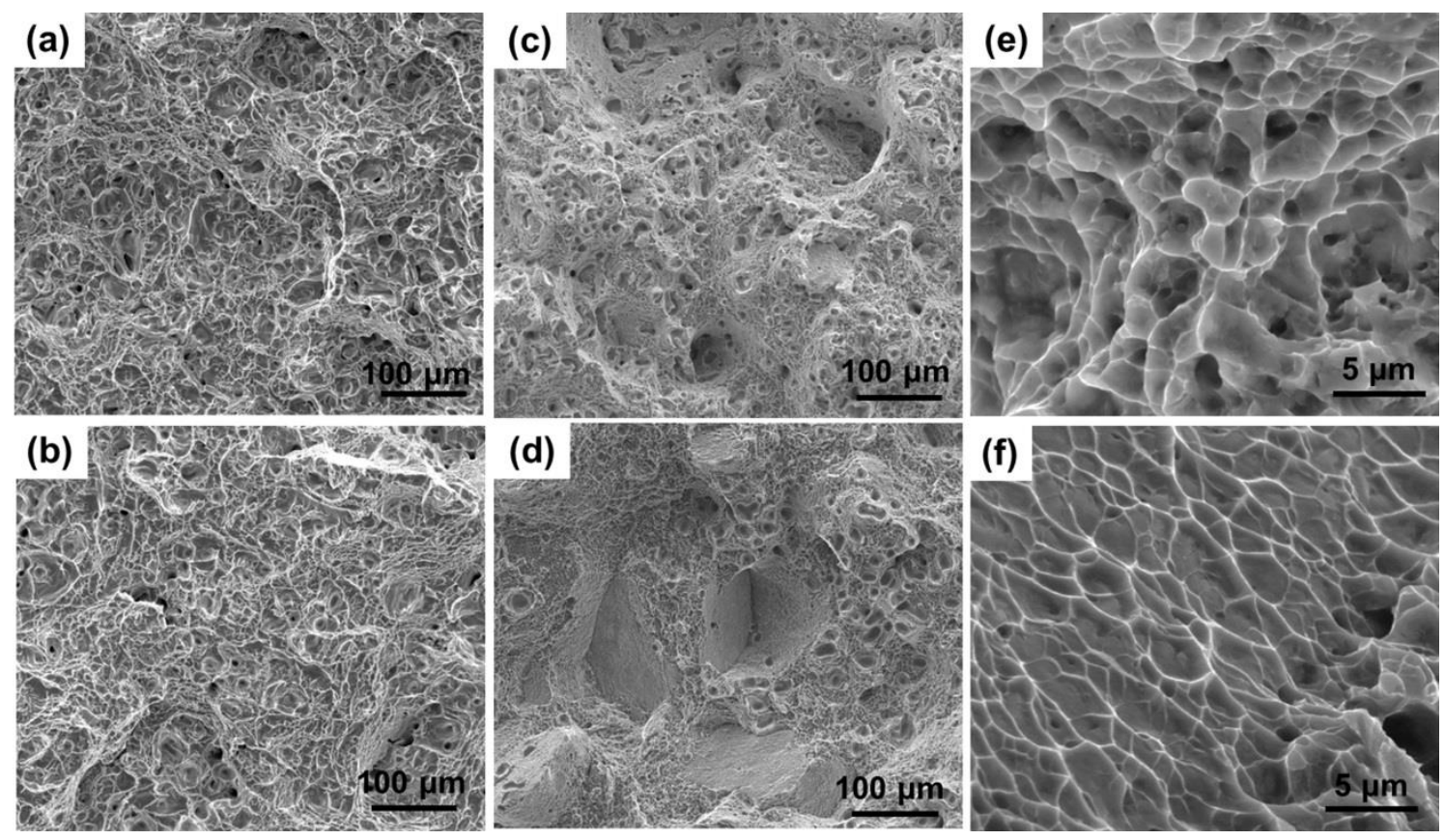

Fig. 4 Fractographs of tensile fracture in PM Ti-6Al-4V samples, (a) 1010VS, (b) 1200VS, (c) 1010VSHDH, and (d) 1200VSHDH, (e) magnified view of (c), (f) magnified view of intergranular fractured region in (d). 


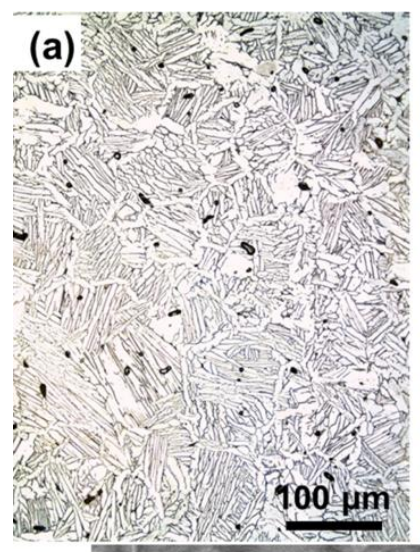

(b)

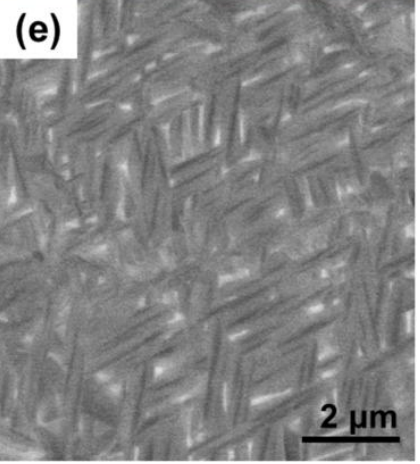

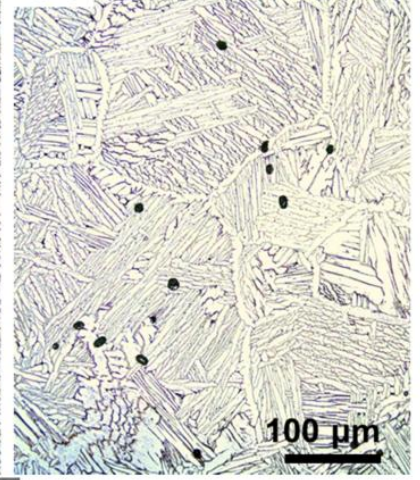

${ }_{8566}{ }_{36669} \mathrm{VK}$

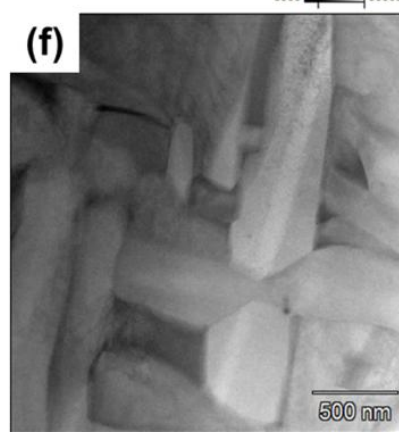

(g) (c)

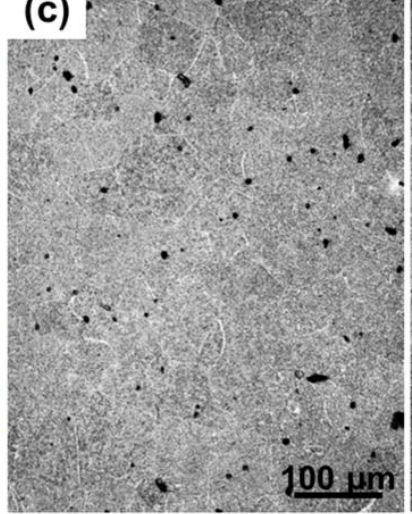

(d)

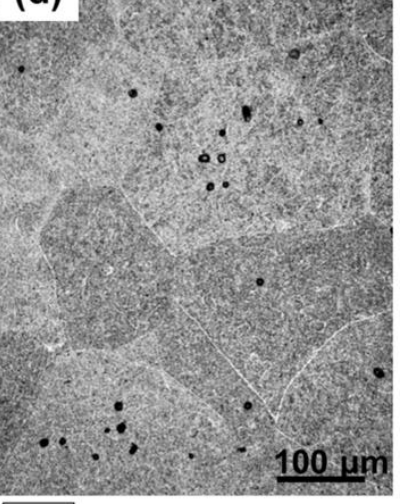

(h)

$1 \longdiv { 1 }$
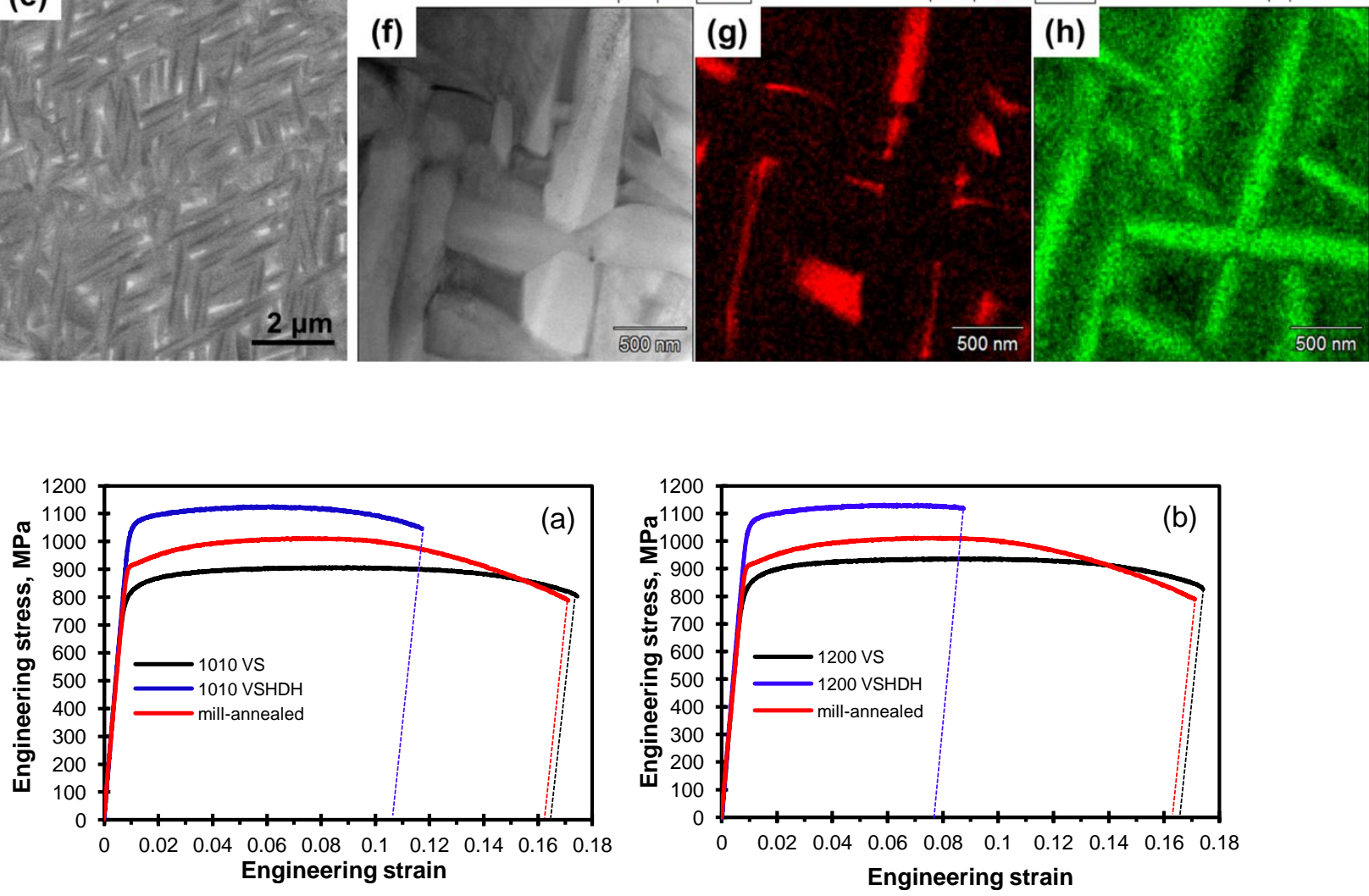